\title{
Implementasi Resource Assignement Algorithm Pada Aplikasi Bahasa Latin Flora Dan Fauna Untuk Pelajar Berbasis Android
}

\author{
Ardi Wijaya ${ }^{1}$, Eka Sahputra², Resnita Kornengsih ${ }^{3}$ \\ 1,2,3Program Studi Teknik Informatika Fakultas Teknik Unniversitas Muhammadiyah Bengkulu Jln.Bali (Telp.(0736) 22027, \\ 22765 Fax.(0736) 26161; e-mail: ${ }^{1}$ ardiwijaya@umb.ac.id ${ }^{2}$ ekasahputra@ umb.ac.id ${ }^{3}$ resnita.kornengsih@gmail.co.id
}

\begin{abstract}
To foster student enthusiasm for learning, teachers are required to make learning more interesting and innovative. The efforts to achieve interesting and innovative learning are to use learning media. Besides, the difficulty of learning Latin makes children less interested because it uses language that is difficult to understand and pronounce. Utilizing mobile devices as a medium for learning makes it easy for the students to learn practically whenever and wherever with the mobile. Resource Assignment Algorithm (RAA) has the ability to produce a value based on several values that are sorted using priority scale. In its application to the introduction of the Latin language of flora and fauna for junior high school students to be generated is the value to execute a decision in answering a question from the Latin language learning of flora and fauna. Based on system testing with User Statisfaction Testing, the results showed $\mathbf{7 2 \%}$ very interesting, $21 \%$ interesting and $7 \%$ not interesting. These results indicate that the design of the application is good and suitable for use.
\end{abstract}

Keywords: Application, Latin Language, RAA, Android

Intisari - Beberapa penelitian menyebutkan adanya masalah yang muncul dari aktifitas bermain game yang berlebihan, masalah tersebut adalah kehilangan kontol atas waktu dan mengalami kesulitan dalam hal akademis. Untuk menumbuhkan semangat belajar siswa, guru dituntut untuk membuat pembelajaran lebih menarik dan inovatif, usaha untuk mencapai pembelajaran yang menarik dan inovatif yaitu dengan menggunakan medi pembelajaran. Sulitnya belajar bahasa latin membuat anak kurang tertarik karena menggunakan bahasa yang sulit dimengerti serta diucapkan. Memanfaatkan mobile device sebagai media untuk belajar memberi kemudahan bagi pelajar untuk belajar secara praktis kapanpun dan dimanapun dengan mobile. Resource Assignment Algorithm (RAA) mempunyai kemampuan untuk menghasilkan sebuah nilai berdasarkan beberapa nilai yang ada dengan diurutkan menggunakan skala prioritas. Pada penerapannya aplikasi pengenalan bahasa latin flora dan fauna untuk pelajar SMP yang akan dihasilkan adalah nilai untuk mengeksekusi sebuah keputusan pada pelajar dalam menjawab sebuah pertanyaan dari pembelajaran bahasa latin flora dan fauna. Berdasarkan pengujian sistem dengan User Statisfaction Testing menunjukkan hasil $72 \%$ sangat menarik, $21 \%$ menarik dan $7 \%$ tidak menarik. Hasil ini menunjukkan rancangan aplikasi dinyatakan baik dan layak digunakan.

Kata Kunci : Aplikasi, Bahasa Latin, RAA, Android

\section{Pendahuluan}

Secara umum pengertian pembelajaran adalah proses interaksi antara peserta didik atau siswa dengan pendidik atau guru dan sumber belajar pada suatu lingkungan belajar yang meliputi guru dan siswa yang saling bertukar informasi.

Penelitian mengenai akibat dari penggunaan teknologi komputer diawali oleh penelitian yang membahas fenomena internet addiction dan kini mulai mengkaji fenomena online game [1].

Untuk menumbuhkan semangat belajar siswa, maka guru dituntut untuk membuat pembelajaran lebih menarik dan inovatif, sehingga mendorong siswa dapat belajar secara optimal baik dalam belajar individual maupun dalam proses pembelajaran di dalam kelas [2].

Nama ilmiah dari makhluk hidup terutama hewan dan tumbuhan merupakan salah satu hal yang pada dasarnya sangat menarik untuk dipelajari dan diketahui. Tetapi pada umumnya para siswa terutama bagi mereka yang sedang mempelajari nama ilmiah hewan dan tumbuhan mengalami kesulitan dalam mempelajari nama ilmiah tersebut karena semua menggunakan bahasa latin atau Bahasa Biologi [3].

Berdasarkan wawancara dengan guru mata pelajaran Biologi kelas VII SMPN 17 Kota Bengkulu, belajar Biologi dikelas VII memberikan informasi tentang Bahasa Latin Flora dan Fauna yang dipelajari pada materi Klasifikasi Makhluk Hidup. Namun sulitnya belajar Bahasa Latin membuat anak kurang tertarik untuk belajar karena menggunakan Bahasa yang sulit dimengerti serta sulit untuk diucapkan. Berdasarkan uraian di atas diperlukan suatu inovasi untuk mengembangkan sebuah media pembelajaran agar membantu guru untuk membuat anak tertarik dalam belajar Bahasa Latin Flora dan Fauna kepada siswa kelas VII. 
Memanfaatkan mobil device sebagai media untuk belajar dapat memberi kemudahan bagi pelajar untuk belajar secara praktis kapanpun dan dimanapun dengan mobile. Resource Assignment Algorithm (RAA) mempunyai kemampuan untuk menghasilkan sebuah nilai berdasarkan beberapa nilai yang ada dengan diurutkan menggunakan skala prioritas [4].

\section{TINJAUAN PUSTAKA}

Penelitian sebelumnya menjelaskan bagaimana membuat NPC (Non Playable Character) pada game TBS mobile yang memiliki kemampuan yang dapat memperhitungkan kondisi yang dialami sebagai dasar keputusan yang akan diambil. Resource Assigment Algorithm (RAA) dipilih untuk menyelesaikan masalah tersebut, karena algoritma RAA mempunyai kemampuan untuk menghasilkan sebuah nilai berdasarkan beberapa nilai yang ada dengan diurutkan menggunakan skala prioritas [4].

\section{A. Resource Assignment Algorithm}

Algoritma Resource Assignment (RAA) adalah sebuah algoritma yang dapat menentukan sebuah nilai untuk sebuah objek yang memiliki resource berdasarkan nilai resource yang berasal dari objek lain maupun objek itu sendiri. Dengan kata lain, RAA adalah algoritma yang bergantung pada nilai resource yang dimiliki oleh objekobjek dalam menentukan sebuah nilai untuk sebuah objek. Algoritma ini memiliki tiga parameter utama yaitu objects, resource dan modifier. Secara keseluruhan algoritma ini terbagi menjadi empat bagian yaitu gather task, generate all possible assignments, sort possible assignment according to score dan assign to task doers [4].

\section{B. Android}

Android adalah sebuah sistem operasi untuk perangkat mobile berbasis linux yang mencakup sistem operasi, middleware, dan aplikasi. Android menyediakan platform terbuka bagi para pengembang untuk menciptakan aplikasi mereka. Android adalah sistem operasi yang menghidupkan lebih dari satu miliar smartphone dan tablet. Karena perangkat ini membuat hidup kita begitu manis, maka setiap versi Android dinamai dari makanan penutup (dessert) [5] .

\section{Pengertian Bahasa Latin}

Bahasa Latin adalah sebuah bahasa Italik yang berasal dari Latium, sebuah daerah di Italia sekeliling kota Roma yang termasuk dalam rumpun Indo Eropa. Bahasa ini menjadi penting karena munculnya kekaisaran Romawi dimana bahasa Latin adalah bahasa resminya. Pada puncak kejayaan kerajaan ini, bahasa Latin dituturkan dari pulau Britania di barat laut sampai Palestina di ujung tenggara dengan kata lain menjadi bahasa Internasional [3].

\section{Pengertian Flora dan Fauna}

Tumbuhan adalah organisme benda hidup yang terkandung dalam alam Plantae. Biasanya, organisme yang menjalankan proses fotosintesis adalah diklasifikasikan sebagai tumbuhan. Hewan atau binatang atau margasatwa atau satwa saja adalah kelompok organism yang diklasifikasikan dalam kerajaan Animalia atau Metazoa, adalah salah satu dari berbagai makhluk hidup yang terdapat di alam semesta [3].

\section{III.METODOLOGI PENELITIAN}

Metode pengembangan sistem menggunakan metode Incremental, Incremental model adalah model pengembangan sistem pada software engineering berdasarkan requirement software yang dipecah menjadi beberapa fungsi atau bagian sehingga model pengembangannya secara bertahap. Metode yang digunakan dalam pembangunan perangkat lunak ini terdiri dari mengikuti model pengembangan incremen (Incremental development model). Incremental model dipilih karena metode ini dapat meminalisir ketidak sesuaian dalam pengembangan perangkat lunak [6].

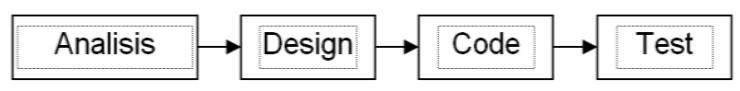

\section{A. Analisis}

\section{Analisis pengumpulan data}

a) Wawancara

Wawancara dilakukan secara langsung dengan guru yang mengajar mata pelajaran Biologi kelas 
VII di SMPN 17 Kota Bengkulu yang bernama Detah Juniarti S.Pd untuk mengetahui data yang lengkap mengenai materi bahasa latin Flora dan Fauna.

b) Observasi

Observasi dilakukan dengan mengamati secara langsung untuk melihat kegiatan dan pristiwa yang dilakukan antara guru dan pelajar. Observasi ini untuk mengetahui informasi yang tidak diperoleh melalui teknik wawancara.

c) Studi Pustaka

Studi Pustaka ini diperoleh peneliti dengan mengumpulkan data yang berasal dari bahan pustaka seperti jurnal-jurnal tentang Pembelajaran Berbasis Android ataupun jurnal tentang Pembelajaran Bahasa Latin.

2. Analisis Pengolahan Data

Pada tahap ini pengolah data dilakukukan dengan metode pengolahan data Kualitatif karna data kualitatif menggunakan teknik non statistik, data yang diperoleh dalam bentuk narasi atau kata-kata bukan angka-angka. Pengolahan data kualitatif dalam penelitian akan melalui tiga proses analisis yakni reduksi data, penyajian data dan menarik kesimpulan.

3. Analisis Alat Dan Bahan

Untuk perancangan aplikasi pembelajaran Bahasa Latin untuk pelajar menengah pertama berbasis android menggunakan Resource Assignment Algorithm, RAA ini menggunakan 2 buah sistem, yaitu server untuk memasukkan data materi dan soal sedangkan smartphone untuk pengujian materi dan soal bagi siswa.

\section{B. Design}

1. Design UML
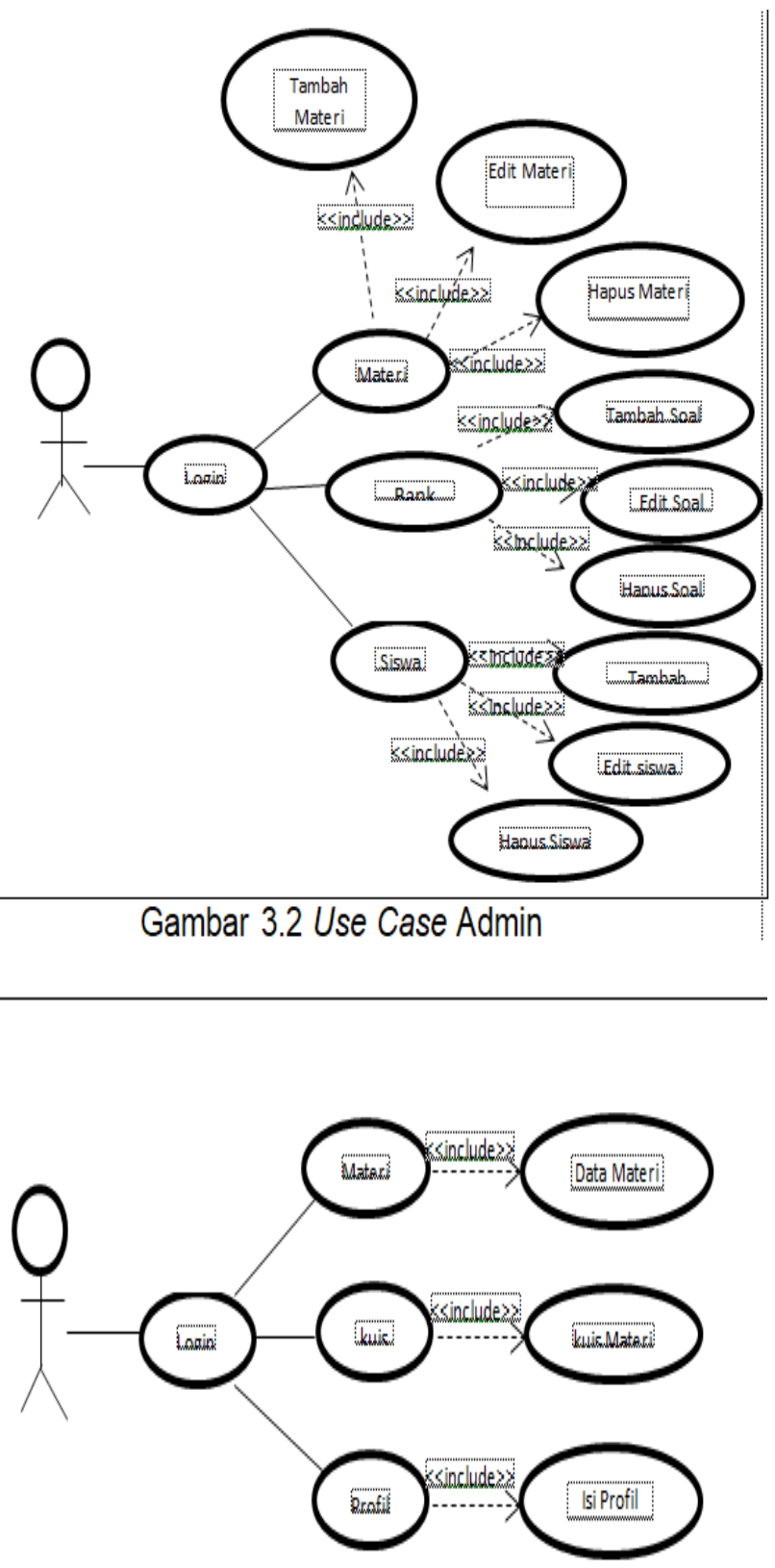

Gambar 3.3 Use Case Siswa 
2. Rancangan Interface

a. Rancangan menu utama

Rancangan menu merupakan tampilan menu utama, pada rancangan menu terdapat 3 menu, yaitu materi, kuis, dan profil.

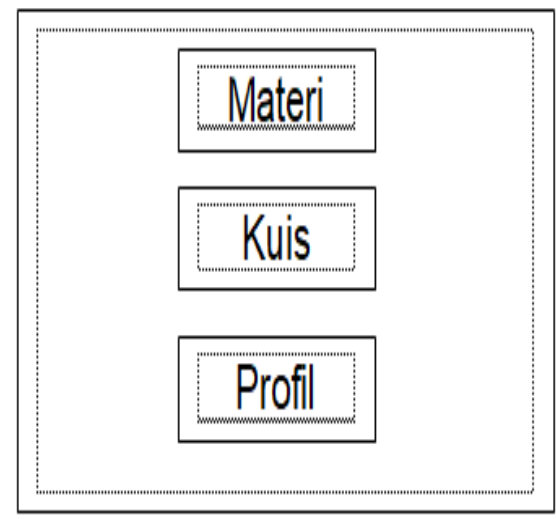

\section{Gambar 3.13 Rancangan Menu Utama}

b. Rancangan menu materi

Pada menu materi merupakan informasi dari dua data materi yaitu Flora dan Fauna.

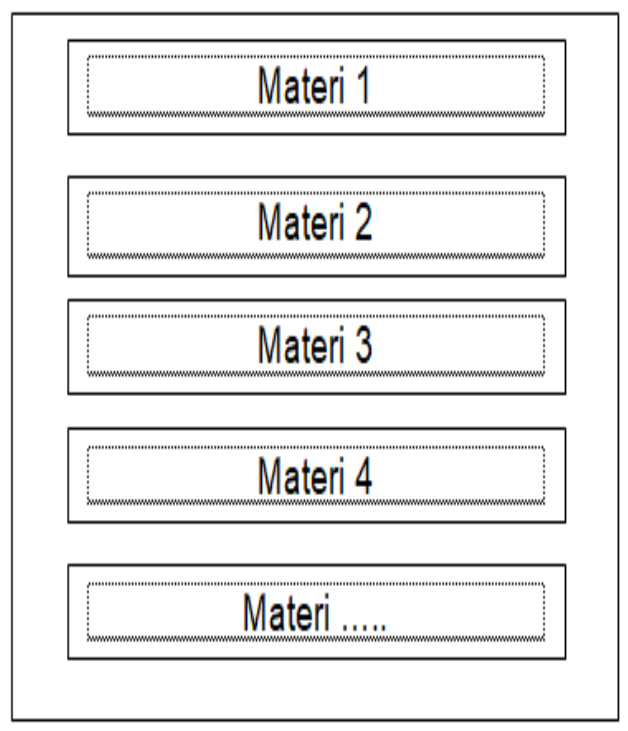

Gambar 3.14 Rancangan Menu Materi c. Rancangan menu kuis

Pada menu kuis merupakan informasi data dari materi, berisikan soal pertanyaaan sesuai dengan materi yang telah dipelajari, soal kuis bersifat fleksibel karena dapat di inputkan pada server.

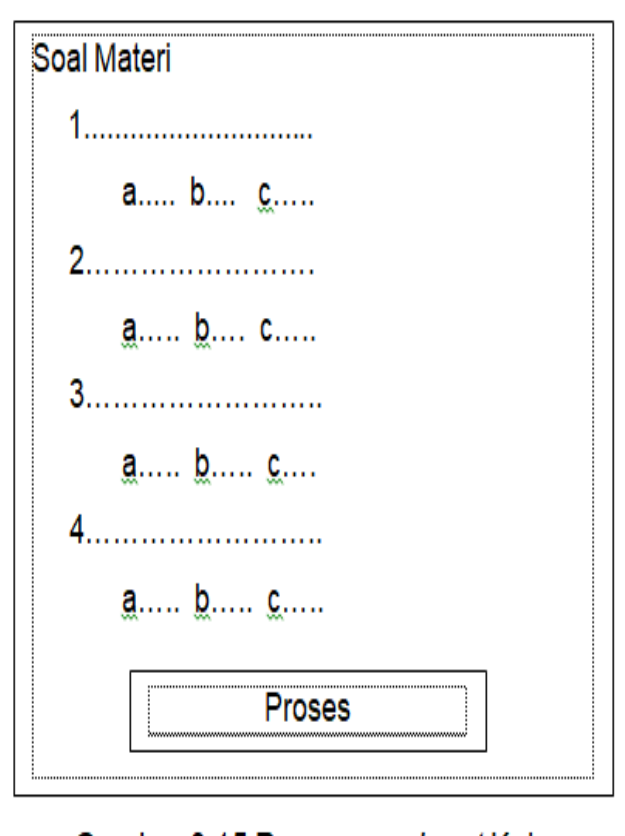

\section{Gambar 3.15 Rancangan Input Kuis}

C. Code

Pada tahap ini merupakan desain yang telah ditetapkan kedalam bahasa pemrograman yang dimengerti komputer. Dalam penelitian ini bahasa pemrograman yang akan digunakan adalah java menggunakan editor android studio 3.4, PHP, MySQL.

D. Test

Proses pengujian sistem dilakukan dengan metode User Statisfaction Testing. User Statisfaction Testing merupakan proses pengujian untuk mengukur semua kegunaan atribut oleh pengguna aplikasi. Yang mana pada penelitian ini di tinjau dari segi kemudahan dalam menggunakan aplikasi, fungsi aplikasi serta memudahkan dalam pemahaman penggunaan aplikasi. Maka oleh karena itu dilakukan User Statisfaction Testing dengan membuat pertanyaan berupa kuisoner untuk mengetehui kepuasan dari pengguna aplikasi.

\section{IV.HASIL DAN PEMBAHASAN}

A. Hasil sistem

Adapun hasil sistem untuk menerapkan Resource Assignment Algorithm pada aplikasi bahasa Latin Flora 
dan Fauna untuk Pelajar berbasis android sehingga menghasilkan aplikasi yang dapat membantu Pelajar SMP dalam penguasaan bahasa Latin Flora dan Fauna yang dilengkapi dengan mini game sehingga pembelajaran bahasa Latin Flora dan Fauna dapat menarik perhatian pelajar.

1. Tampilan login

Halaman login merupakan input data siswa berdasarkan NIS pada admin.

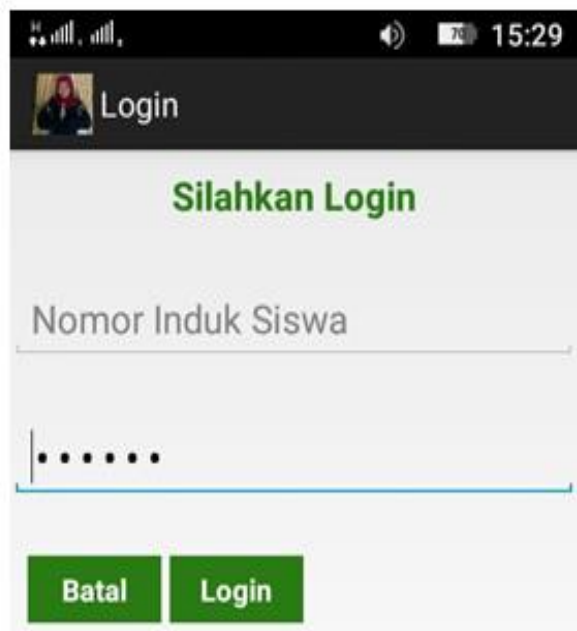

\section{Gambar 4.7 Tampilan Login}

2. Tampilan menu utama

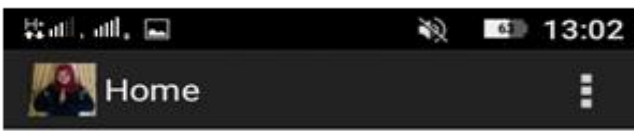

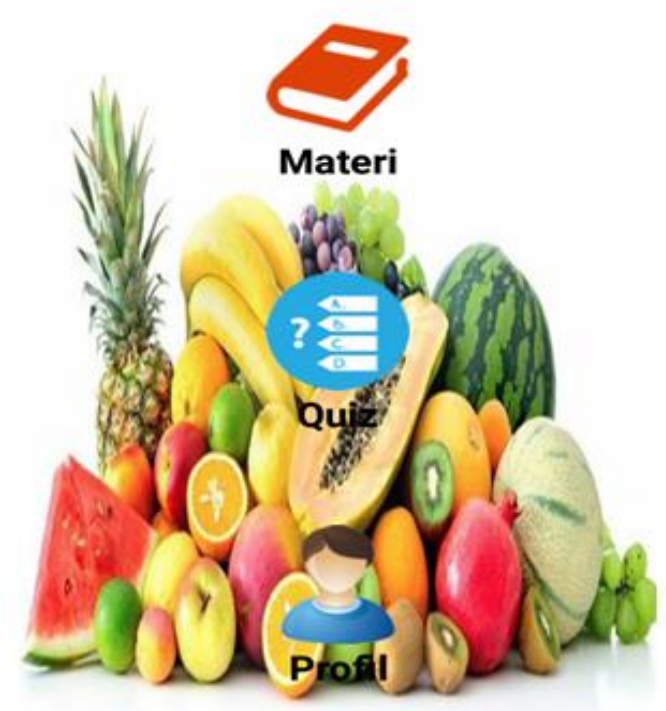

Gambar 4.8 Tampilan Menu Utama
3. Tampilan menu materi

Pada menu materi merupakan informasi data materi, berisikan informasi judul dan isi dari materi tersebut.

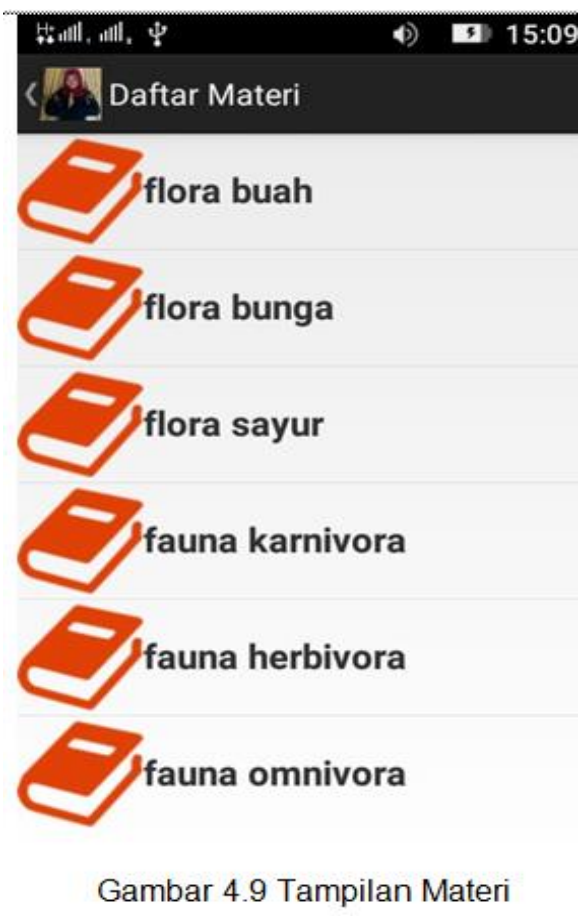

4. Tampilan menu kuis

1.) Pyrus malus merupakan bahasa latin
dari buah?
apel
pisang
alpukat
2.) bahasa latin dari mangga yaitu?
Punica granatum
mangifera kemanga
mangifera indica

Gambar 4.12 Tampilan Detail Kuis 
5. Tampilan hasil kuis

\section{Hasil Nilai Kuis}

$$
\begin{aligned}
& \text { No } 1 \text { salah } \\
& \text { No } 2 \text { benar } \\
& \text { No } 3 \text { benar } \\
& \text { No } 4 \text { benar } \\
& \text { No } 5 \text { benar }
\end{aligned}
$$

\section{Score $=4$}

\section{Gambar 4.13 Tampilan Hasil Kuis}

\section{B. Pengujian Sistem}

Pengujian sistem dilakukan setelah aplikasi yang dibuat telah selesai. Proses pengujian sistem dilakukan dengan User Statisfaction Testing. Pengujian perencanaan menggunakan kuesioner dari User Statisfaction Testing.

\begin{tabular}{|c|c|c|c|c|}
\hline \multirow{2}{*}{ No } & \multirow{2}{*}{ Kriteria } & \multicolumn{3}{|c|}{ Persentase $\%$} \\
\hline & & SM & $M$ & TM \\
\hline 1 & Program bersifat Interaktif dan Dinamis & 16 & 3 & 1 \\
\hline 2 & $\begin{array}{l}\text { Aplikasi membantu informasi pembelajaran } \\
\text { bahasa latin }\end{array}$ & 17 & 3 & 0 \\
\hline 3 & $\begin{array}{l}\text { Bagaimana pemahaman materi pada } \\
\text { aplikasi pembelajaran bahasa latin sesuai } \\
\text { dengan kebutuhan }\end{array}$ & 14 & 4 & 2 \\
\hline 4 & Warna tampilan menarik & 13 & 5 & 2 \\
\hline 5 & Menu tampilan bersifat user friendly & 12 & 6 & 2 \\
\hline & Jumlah Responden & \multicolumn{3}{|c|}{20} \\
\hline
\end{tabular}
Akan diajukan pertanyaan yang telah menjadi indikator pada User Statisfaction Testing.

Adapun tampilan pengujian sistem dengan menggunakan kuisioner dapat dilihat di bawah ini :

Keterangan :

1. Jumlah pertanyaan :
a. Sangat Menarik $=72$ Pertanyaan
b. Menarik = 21 Pertanyaan
c. Tidak Menarik $=7$ Pertanyaan

Total 100

2. Jumlah Responden : 20 Responden

Maka diperoleh jawaban sangat menarik $72 \%$, menarik $21 \%$, dan tidak menarik 7\%. Adapun cara perhitungannya adalah sebagai berikut :

1. Hitung setiap row pernyataan kemudian pernyataan dijumlahkan.

2. Lakukan penghitungan :

a. Sangat Menarik

$$
\frac{72}{100} x 100 \%=72 \%
$$

b. Menarik

$$
\frac{21}{100} \times 100 \%=21 \%
$$

c. Tidak menarik

$$
\frac{7}{100} \times 100 \%=7 \%
$$

\section{KESIMPULAN DAN SARAN}

A. Kesimpulan

Kesimpulan yang dapat ditarik dari sistem Implementasi Resource Assignment Algorithm pada aplikasi Bahasa Latin Flora dan Fauna untuk Pelajar berbasis android (studi kasus SMPN 17 Kota Bengkulu), adalah sebagai berikut :

1. Menghasilkan aplikasi yang dapat membantu Pelajar kelas VII SMPN 17 Kota Bengkulu dalam pembelajaran bahasa Latin Flora dan Fauna yang dilengkapi dengan mini game sehingga penguasaan Bahasa Latin dapat bertambah banyak dan luas.

2. Untuk menerapkan resource assignment algorithm pada aplikasi bahasa Latin Flora dan Fauna untuk Pelajar berbasis android sehingga menambah ilmu pengetahuan dan sebagai bahan untuk pengembangan Fakultas Teknik Program Studi Informatika

3. Dapat memberikan informasi pembelajaran Bahasa Latin Flora dan Fauna yang secara mudah, efektif dan efisien. 
4. Berdasarkan pengujian sistem dengan User Statisfaction Testing menunjukkan hasil $72 \%$ sangat menarik, 21\% menarik dan $7 \%$ tidak menarik. Hasil ini menunjukkan rancangan aplikasi dinyatakan baik dan layak digunakan.

B. Saran

Dari kesimpulan diatas, ada beberapa saran agar dapat menggunakan program aplikasi ini dengan maksimal.

1. Diharapkan aplikasi ini selalu up to date sehingga aplikasi ini mengikuti perkembangan teknologi informasi pendidikan

2. Diharapkan pengembangan aplikasi ini dapat menjadi referensi bukan hanya dunia pendidikan juga untuk semua kalangan sebagai perkemangan informasi teknologi.

3. Diharapkan aplikasi ini dapat dikembangkan pada kasus lainnya sehingga dapat menambah wawasan pada pemograman java.

\section{DAftar Pustaka}

[1] Syahran Ridwan. 2015. Ketergantungan Online Game Dan Penanganannya. Jurnal Psikologi Pendidikan \& Konseling.

[2] Yuliandari, Wahjudi. 2014. Pengembangan Media Pembelajaran Berbasis Multimedia Interaktif Pada Mata Pelajaran Ekonomi Materi Jurnal Penyesuaian Perusahaan Jasa. Jurnal Mahasiswa,

[3] Ruslan, Pramono, Subardin. 2016. Aplikasi Kamus Bahasa Latin Hewan Dan Tumbuhan Menggunakan Metode Brute Force Dan Fitur Autocomplete Berbasis Android. semantic,.

[4] Utomo, Widiastuti. 2013. Turn Bassed Strategi Game Menggunakan Algoritma Resource Assignment Pada Perangkat Mobile Berbasis Android. Jurnal Ilmiah dan Informatika.

[5] Putra, Wahyu, dkk. 2016. Game Edukasi berbasis android sebagai media pembelajaran untuk anak usia dini, jurnal informatika merdeka pasuruan,.

[6] R. S. Pressman, "The Incremental Model," in Software Engineering, A Practitioner's Approach,
New York, McGraw-Hill Series in Computer Science, p. 36.

[7] Hendini. 2016. Pemodelan Uml Sistem Informasi Monitoring Penjualan Dan Stok Barang (Studi Kasus: Distro Zhezha Pontianak). Jurnal Khatulistiwa Informatika.

[8] Amri, Sarkum, Purnama. 2018. Media Pembelajaran Kamus Bahasa Latin Berbasis Android. Jurnal Nasional Informatika Dan Teknologi Jaringan,

[9] Juansyah. 2015. Pembangunan Aplikasi Child Tracker Berbasis Assisted - Global Positioning System (A-Gps) Dengan Platform Android. Jurnal Ilmiah Komputer dan Informatika (KOMPUTA).

[10] Nuraini. 2015. Desain Algorithma Operasi Perkalian Matriks Menggunakan Metode Flowchart. Jurnal Teknik Komputer Amik Bsi.

[11] Nurhayati, Nagara. 2015. Sistem Pendukung Keputusan Penentuan Hama Padi Menggunakan Php. Jurnal TAM (Technology Acceptance Model.)

[12] Maryuliana. 2015. Sistem Informasi Angket Pengukuran Skala Kebutuhan Materi Pembelajaran Tambahan Sebagai Pendukung Pengambilan Keputusan Di Sekolah Menengah Atas Menggunakan Skala Likert. Jurnal Transistor Elektro Dan Informatika (TRANSISTOR).

[13] Sitohang. 2018. Sistem Informasi Pengagendaan Surat Berbasis Web Pada Pengadilan Tinggi Medan. Journal Of Informatic Pelita Nusantara. 